\title{
Using a laser measurement system for monitoring morphological changes on the Strug rock fall, Slovenia
}

\author{
M. Mikoš, A. Vidmar, and M. Brilly \\ Faculty of Civil and Geodetic Engineering, University of Ljubljana, Ljubljana, Slovenia \\ Received: 14 September 2004 - Revised: 12 January 2005 - Accepted: 23 January 2005 - Published: 28 January 2005 \\ Part of Special Issue "Landslides and debris flows: analysis, monitoring, modeling and hazard"
}

\begin{abstract}
A medium-ranged high performance handheld reflectorless laser measurement system, was used for a morphological survey on the Strug rock fall in W Slovenia in the period from August 2003 to August 2004. The purpose was to evaluate its potential for monitoring ground surface changes in rock fall source areas and to help evaluating morphological changes by measuring distance from fixed points. In the area, 21 fixed geodetic points have been established. Altogether, seven measurement sets with more than 5500 points have been gathered in the rock fall area. Choosing a point cloud with a density of less than 1 point per $10 \mathrm{~m}^{2}$ on a very rough rock fall surface failed to be a good solution. The changes on larger areas were shown by displacements of selected significantly large-sized rock blocks with a volume of several $\mathrm{m}^{3}$. Because only smaller changes were observed between the single field series, the rock fall surface generally remained unchanged. Local surface changes of the order of $1 \mathrm{~m}$ or more, were clearly shown by measurements in the selected referenced cross sections. The usage of these cross sections gave a possibility to evaluate volumetric changes on the surface. The laser measurement system provided a good replacement for the classical terrestrial geodetic survey equipment, especially when performing remote monitoring of morphological changes in rock fall hazard zones, however, the case is different when fixed points are to be measured precisely.
\end{abstract}

\section{Introduction}

There is a requirement for rapid and remote monitoring of rock faces especially rock fall source areas in order to evaluate their dynamics and potential hazard. The rapid development of various surveying approaches has opened wide possibilities for advanced monitoring of different slope instability processes, such as landslides, rock falls, mudflows and de-

Correspondence to: M. Mikoš

(matjaz.mikos@fgg.uni-lj.si) bris flows. These methodologies can be divided on one hand into point-based (Total Station, GPS) and area-based techniques (Photogrammetry, Laser Scanning, and Remote Sensing) (Bitelli et al., 2004) and on the other hand to spaceborn, airborn or terrestrial techniques. The ground-based techniques are increasingly being combined with other classical research field techniques widely used, such as extensometers, inclinometers, video cameras (Angeli et al., 2000). All the measured field data can be put into a geodetic database (Jaboyedoff et al., 2004).

For continuous observations on landslides and rock falls various ground-based techniques were successfully applied under real field conditions, such as digital photogrammetry combined with Global Positioning System (Mora et al., 2003), static and real kinematic GPS methods (Gili et al., 2000), ground-based SAR interferometry (Tarchi et al., 2003) or laser scanner (Scheikl et al., 2001).

These techniques can be coupled with a warning system for landslide hazard management or used to develop multitemporal Digital Terrain Models (DTMs) that provide information on geometry, changes of volumes, and evolution of phenomena, such as its displacement or virtual velocity (Mora et al., 2003). Since each landslide is different and thus characterised by the way it has developed, it is necessary to choose an adequate monitoring system on the basis of the preliminary analysis of a phenomenon (Mora et al., 2003).

For rock falls with high activity it is not wise to plan a monitoring system using Electronic Distance Meters (EDMs) or the Electronic Theodolite and fixed reflecting prisms that might be easily destroyed. Similarly, it is not advisable to perform regular measurements by walking with reflectors on the rock fall surface. For rock falls or similar hazardous conditions as are prevailing in the case of volcanoes a laser scanner system is often used for monitoring purposes (Scheikl et al., 2001; Hunter et al., 2003). Terrestrial Laser Scanners (TLS) are designed to digitise geometry of real environments with high precision and high accuracy. They enable non-contact measurements of thousands of single points in the form of point clouds in a rather short 


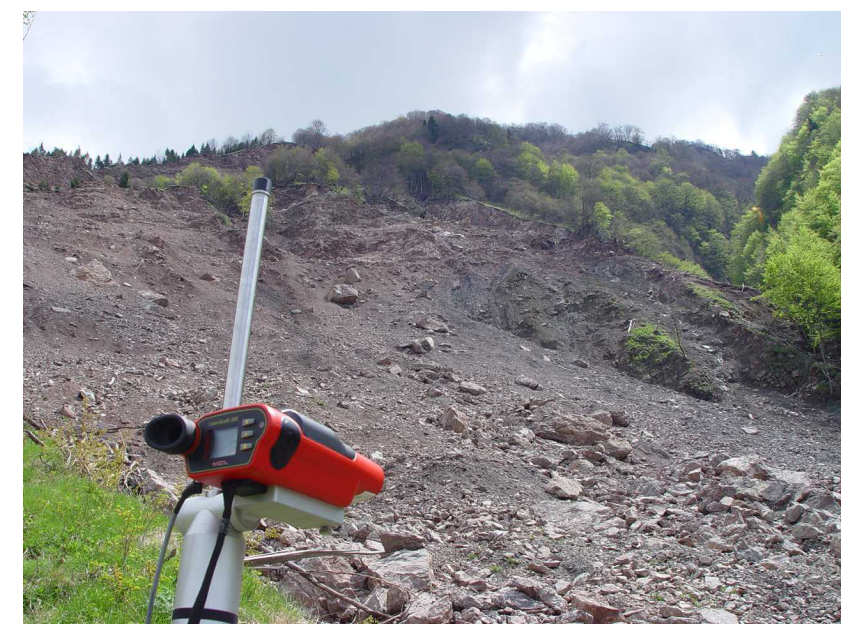

Fig. 1. Upslope view of the Strug rock fall source area from the fixed geodetic point "ST_KOS1" towards the scar of the rock fall.

time. When choosing an adequate laser scanner measurement system (medium-range, long-range), it should also be cost-effective.

For the Strug rock fall triggered on 22 December, 2001 spreading over an area of 6.02 ha (Mikoš et al., 2005) a handheld laser measurement system used on a tripod rather than a more expensive laser scanner was selected in order to monitor morphological changes on its surface.

\section{The Strug rock fall test area}

The Strug rockslide above the Kosec village near Kobarid in the Julian Alps, W Slovenia, was initiated in December 2001 (Fig. 1). It had an estimated volume of $95000 \mathrm{~m}^{3}$ and was triggered on the contact between high permeable calcareous rocks (Cretaceous scaglia) thrusted over nearly impermeable clastic rocks (Cretaceous flysch) (Fig. 2). After a sudden drop of $15 \mathrm{~m}$ in December 2001, the rockslide average velocity exponentially slowed down to less than $10 \mathrm{~m} /$ year till the end of 2002, and came to a practical stillstand in 2003.

Soon after the rockslide initiation a rock fall with a volume of $45000 \mathrm{~m}^{3}$ was initiated on 22 December 2001 within the rockslide. The kinetic push of the rock fall caused a movement of a translational soil landslide with a volume of $180000 \mathrm{~m}^{3}$, which filled up the torrential ravine of the Brusnik Stream (Fig. 2). During the slip of the landslide for some 50 vertical metres, an up to 8-m high scarp was formed due to side relaxation on its right-hand side (looking downslide). This is how the side support of the unstable masses to the right of the landslide decreased and a new smaller landslide commenced. This slide was called the "right-hand side relaxation landslide" and has a volume of approximately $35000 \mathrm{~m}^{3}$.

After the rainfall in spring 2002, small debris flows of a volume of up to $1000 \mathrm{~m}^{3}$ started to flow from the rock fall deposits over the landslide to and along the channel of the
Brusnik Stream. This rather small debris-flow magnitudes are not often reported in literature, but may be very hazardous (Marchi and D'Agostino, 2004). Such small-magnitude debris flows were measured in the Eastern Italian Alps typically for basin areas of less than $1 \mathrm{~km}^{2}$ (D'Agostino and Marchi, 2001), quite comparable to the Strug rock fall case.

The main source for debris flows was a gully that formed in 2002 in the lower accumulation part of the rock fall. In 2002 , more than 20 debris flow events were registered. Locally, the rainfall intensities were measured and a correlation with the debris flow events was established. The analysis showed that debris flows were initiated when the daily rainfall reached more than 20 to $30 \mathrm{~mm} /$ day, depending on the antecedent precipitation (Mikoš et al., 2005). In early 2003 and later on, debris flows were no longer observed and thus a question was raised, whether the frequency of falling stones was much lower than in 2002 and so the debris flow events were mainly governed by the fresh supply of released material in the rock fall source area. With respect to the answer to the raised question, a monitoring system of the rock fall activity and its morphological changes was established in 2003 using laser technology.

\section{Methods}

The medium-ranged LaserAce ${ }^{\circledR} 300$ measurement system (MDL, 2004) is a low-cost but high performance hand-held reflectorless laser measurement system that incorporates an inclinometer and a solid state fluxgate compass (Fig. 1; Table 1).

For best performance, it operates from a tripod by viewing through its viewfinder and by placing the laser beam on the selected point (natural target, reflector) by hand. It is not meant to operate automatically as a full laser scanner. Therefore its output given as the size of the measured point clouds is rather limited. Raw data (distance in metres, horizontal and vertical angle in degrees) can be then transferred to peripheral devices (handheld PC, data loggers) using a standard RS232 serial link.

A pocket computer was used for data collection from the serial port. A computer program was developed in Qbasic (Microsoft, 2004) for handling of raw data and for preparation of a script file for further use in the AutoCAD® environment (output in *.dwg files) (Autodesk, 2004). The QuickSurf 5.1 extension for AutoCAD (Schreiber, 2004) was used for plotting the 3D-georeferenced points and further data analysis (3D TIN, Contour, and Grid models).

In the field, the terrain surface itself and additionally selected significant objects (i.e. large rocks, small ravines or gullies, cracks) were measured. Using these data a composite 3-D Digital Terrain Model were formed. Using the subsequent field measurements, new 3-D models were formed. Together they form a 3-D space and time model. In changes of the model surface were tracking the displacements of single objects. Changes of erosional features locations like gullies were observed within the precision limits of the sys- 


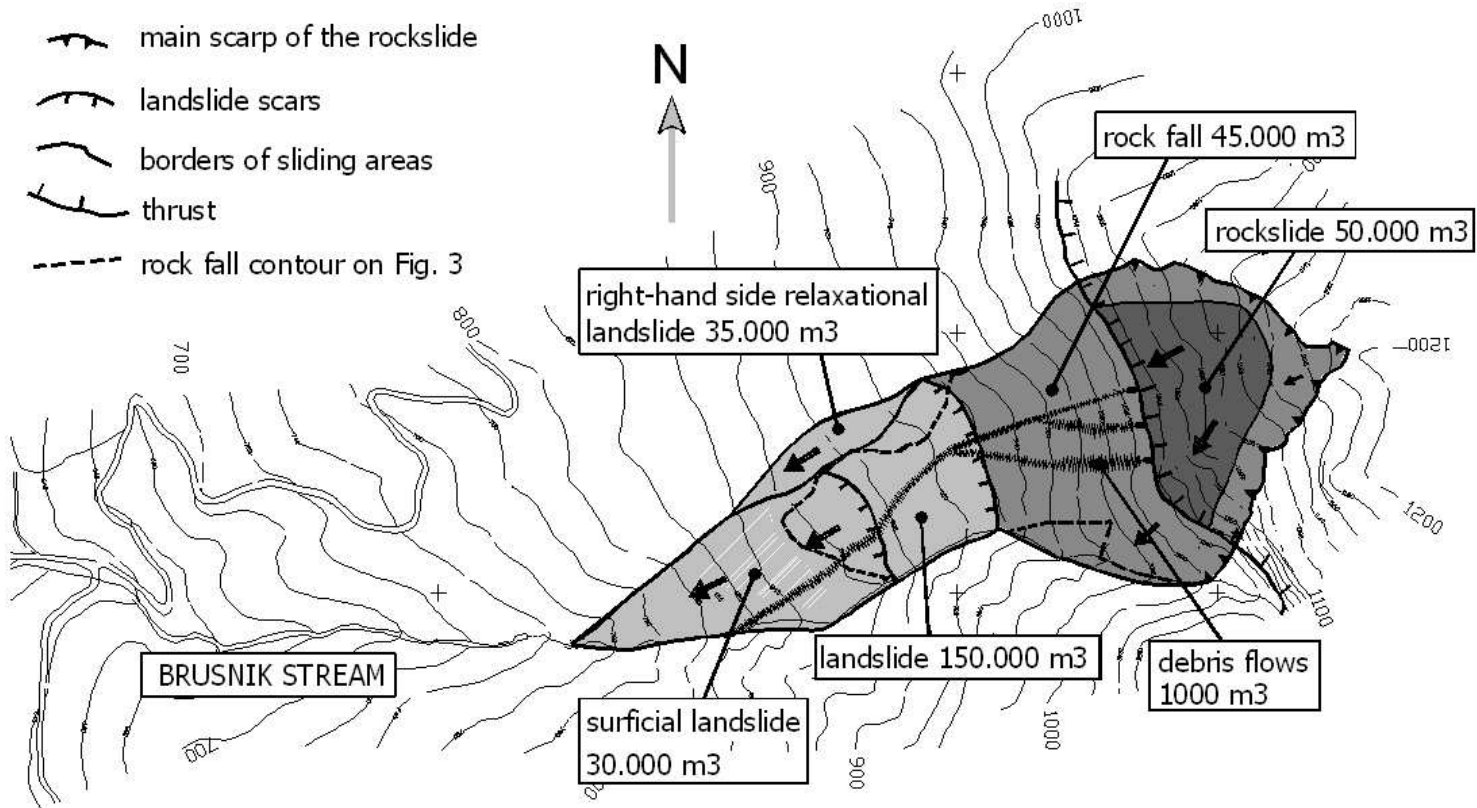

Fig. 2. The Strug rock fall and different slope instability phenomena.

Table 1. Specification of the LaserAce ${ }^{\circledR} 300$ Measurement System (MDL, 2004), powered by 2 internal AA batteries (1.5 V) and weighing only $600 \mathrm{~g}$. The compass is powered by 6 external AA batteries $(1.5 \mathrm{~V})$ and weighs $50 \mathrm{~g}$.

\begin{tabular}{ll}
\hline Measurement parameter & Specification \\
\hline Maximum range & typically $300 \mathrm{~m}$ in passive mode and $5 \mathrm{~km}$ with reflectors \\
Minimum range & $10 \mathrm{~m}$ \\
Accuracy & typically $\pm 10 \mathrm{~cm}$ \\
Resolution & $1 \mathrm{~cm}$ \\
Time & $0.3 \mathrm{~s}$ \\
Beam divergence & approximately $3.1 \mathrm{mrad}$ (i.e. $310 \mathrm{~mm}$ beam width per $100 \mathrm{~m}$ range) \\
Scanning range & $-90^{\circ}$ to $+90^{\circ}$ vertical angle (inclinometer) by $360^{\circ}$ horizontal angle (compass) \\
Inclinometer accuracy & $0.3^{\circ}$ at $0^{\circ}$ \\
Inclinometer resolution & $0.1^{\circ}$ \\
Compass accuracy & typically better than $1^{\circ}$ \\
Compass resolution & $0.1^{\circ}$ \\
\hline
\end{tabular}

tem, which were $\pm 10 \mathrm{~cm}$ under ideal conditions. Fog or rain will hinder the measurements by obscuring the targets or by scattering the laser beam on rain drops. Therefore, the laser measurement system was not used under such field conditions.

The Geodetic Institute of Slovenia prepared a comparison between the topography of the Strug rock fall source area before and after its triggering in December 2001. For the topography before the event, aerial photographs were used from the cyclic campaign, which was performed in August 2000. At that time vegetation was abundant and because the slope was under forest before the event, the topography was rather approximate and thus defined in only some visible points. Also older aerial photographs from 1975 were rather obscured by forest and only some additional terrain points were taken. A map with equidistances at $10 \mathrm{~m}$ was prepared using the computer program QuickSurf® (Schreiber, 2004). Since no old reference geodetic points were available in the area, the precision of this map was assessed as rather bad with no detailed numeric values for precision.

For the determination of 21 fixed geodetic points in the Strug rock fall area, a combined classical terrestrial geodetic surveying and field GPS campaign was performed using three geodetic GPS receivers, type 4000 Ssi from Trimble Navigation (Trimble, 2004), and an electronic Leica tachometer, type TC 603L (Leica, 2004). All computations of raw geodetic data from this survey were done using the software package LisCAD ver. 6.0 (Listech, 2004). The transformation of co-ordinates of the points measured by the GPS survey in the ETRS'89 co-ordinates was applied using 
Table 2. Overview of 21 fixed geodetic points in the Strug rock fall source area (No. 1 through No. 13 are reinforcement iron bars drilled to a rock or terrain with a supplement for a reflector, and No. 14 through No. 21 are CDROMs attached to rocks and trees).

\begin{tabular}{lll}
\hline No. & Point ID & Remarks \\
\hline 1 & ST_KOS1 & rock \\
2 & ST_KOS2 & reflector under large rock \\
3 & ST_KOS3 & large rock \\
4 & ST04 & rock \\
5 & ST05 & nailed into the ground outside the rock fall \\
6 & ST06 & drilled into the ground in the middle of the rock fall \\
7 & ST_VRH & smaller rock above the scar \\
8 & SK_I & rock \\
9 & SK_II & rock \\
10 & SK_III & rock \\
11 & SK_IV & rock \\
12 & SK_V & rock \\
13 & SK_VII & rock \\
14 & CD_1 & tree \\
15 & CD_2 & stable rock in the forest \\
16 & CD_3 & tree in the forest \\
17 & CD_4 & fallen tree on the rock fall \\
18 & CD_5 & tree on a crest on the rock fall \\
19 & CD_6 & tree near the erosive channel \\
20 & CD_I & tree in the slump \\
21 & CD_II & wooden stake at the end of the slump \\
\hline & &
\end{tabular}

spatial 7-parametric Helmert's transformation, so that the positions of these points were afterwards given in the state coordinate system. These 21 fixed points served in 2003 and 2004 as the basic network for geodetic measurements using the laser measurement system and will in future enable further combinations with other geodetic products (i.e. DEM, orthophoto from aerial photographs).

\section{Field measurements}

Parallel to geodetic measurements, rainfall intensities in the Strug rock fall area were measured, using two pluviometers (instruments for measuring the depth of water from precipitation at a point) with the tipping bucket technology and resolution of $0.2 \mathrm{~mm}$, and an event data logger. Raw data were transformed into 10-min rainfall intensities for further analysis.

\subsection{Determination of fixed geodetic points in the area}

The Strug rock fall area is a hard-to-access terrain, so a classical geodetic survey using i.e. an electronic theodolite and reflecting prisms would demand hard fieldwork and might be dangerous. Thus, as part of the field preparation work, altogether 21 geodetic points were fixed in the Strug rock fall area (Table 2). They were put into the state coordinate sys- tem during a combined classical terrestrial geodetic surveying and field GPS campaign on 2 October 2003.

The fixed geodetic points (natural and artificial reflectors) on the Strug landslide (Fig. 3) can be split into the base point "ST_KOS1", the orientation point "ST_KOS3", the stable points "ST_VRH", "ST_KOS2", and "ST04" through "ST06", and the additional points "CD_1" through "CD_II" using CDROMs on trees as reflectors. The CDROMs were quickly removed by wind and rainfall, and later replaced. It can be assumed that the base point "ST_KOS1" and the orientation point "ST_KOS3" were stable during the GPS and the classical terrestrial geodetic survey on 2 October 2003. The stable points "ST_VRH" and "ST_KOS2" lay on the edge of the rock fall source area (Fig. 3).

The surface of the Strug rock fall source is very rough. On such a rough surface the laser device specification, we used, would need to measure roughly 1 point per $1 \mathrm{~m}^{2}$ in order to get a very precise Digital Terrain Model, which was imposible considering the area of 6 ha of the rock fall. The choice was then to measure larger rock blocks with a volume of the order of several $\mathrm{m}^{3}$ as indicators of the rock fall activity. Therefore, six fixed geodetic points "SK_I" through "SK_VI" were chosen on large rocks on the rock fall surface (Fig. 3). These geodetic points were stabilised using a 50$60 \mathrm{~cm}$ long steel reinforcement bars, drilled into the rocks and with a rust-resistant supplement for the reflector on its top. The spatial co-ordinates of these fixed geodetic points were defined indirectly by measuring angles resp. directions and lengths in the geodetic network. The planar co-ordinates were given for the centre of the reinforcement bars and the altitude was given for the contact between the bar and the rust-resistant supplement.

4.2 Geodetic measurements using the laser measurement system

Each geodetic measurement was composed of distance measurements from and to the selected fixed geodetic points (Table 2, Fig. 3), and to selected points on the rock fall surface. Additionally, two cross sections were selected in the accumulation area. The upper cross section "ST_KOS1ST_KOS2" was selected in a steeper terrain and a little bit oblique to the rock fall steepest descent. The lower cross section "ST_KOS1-CD2" was selected in a more gentle terrain. In the upper cross section the lowering of the terrain due to gravity and in the lower cross section accumulation of the rock fall material and its occasional erosion by water have been expected. Also, at the subsequent measurements a gully was observed and its dynamics should help interpret together with the rainfall dynamics in the area the debris flow generation. Figure 3 shows the Strug rock fall area with the used fixed stations and other fixed geodetic points (steel reinforcement bars on rocks and CDROMs on rocks and trees), as well as both measured cross sections and the gullies.

In 2003, four geodetic measurement sets were gathered in the field (Table 3). The measurement set 0 ("zero measurement") on 12 and 13 August 2003 was performed during high 


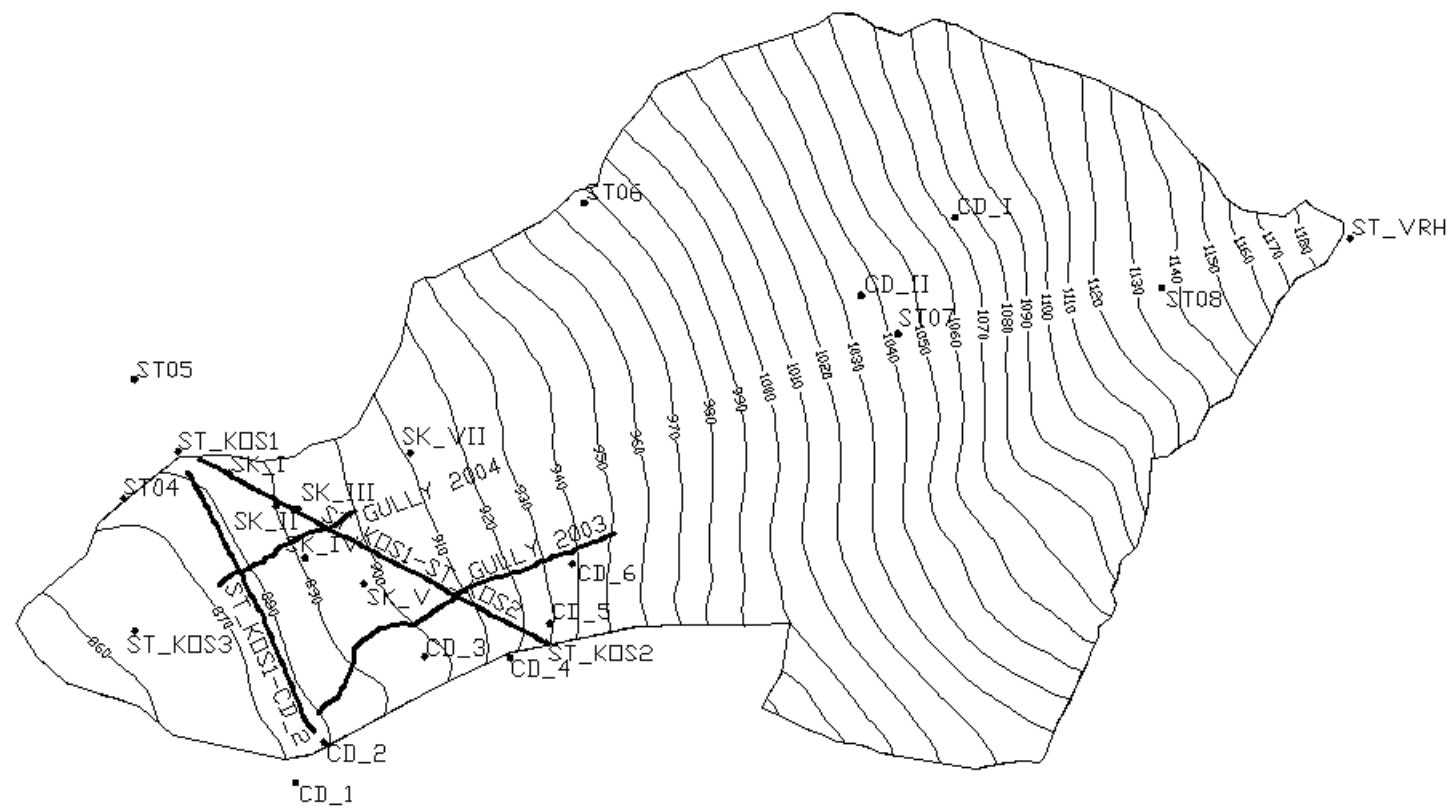

Fig. 3. The Strug rock fall area given as a topographic map with 21 fixed geodetic points, 2 reference cross sections and 2 measured gullies.

Table 3. Dates of all geodetic measurements with the number of measured points, the amount of rainfall in mm and the number of thunderstorms with rainfall $>30 \mathrm{~mm}$ between the measurements.

\begin{tabular}{|c|c|c|c|c|}
\hline Measurement set & Measurement date & $\begin{array}{l}\text { Number of points } \\
\text { measured }\end{array}$ & $\begin{array}{l}\text { Rainfall depth from the } \\
\text { last measurement }(\mathrm{mm})\end{array}$ & $\begin{array}{l}\text { Number of thunderstorms with rainfall } \\
>30 \mathrm{~mm} \text { from the last measurement }\end{array}$ \\
\hline 0 & $12 \& 13$ August 2003 & 1158 & - & - \\
\hline 1 & $3 \& 4$ September 2003 & 1470 & 118.2 & 1 \\
\hline 2 & $1 \& 2$ October 2003 & 778 & 133.0 & 2 \\
\hline 3 & 28 November 2003 & 1253 & 539.6 & 8 \\
\hline 4 & 28 April 2004 & 92 & 678.4 & 8 \\
\hline 5 & 12 May 2004 & 750 & 80.0 & 1 \\
\hline 6 & 3 August 2004 & 112 & 200.0 & 3 \\
\hline
\end{tabular}

air temperatures in sunny weather conditions under local circumstances not allowing to measure large distances. At this measurement several fixed points were selected and labelled by CDROMs. Till the measurement set 1 performed on 3 and 4 September 2003, the majority of CDROMs disappeared. The steel reinforcement bars and rust-resistant supplements for reflectors thus replaced these fixed points.

In the spring of 2004 two new measurement sets 4 and 5 were gathered in April and May after the wet period with mainly rainfall and only occasional snow accumulation (Table 3). The last geodetic measurement set 6 was gathered on 3 August 2004, after a stronger local earthquake on 12 July 2004, with a magnitude of 4.9 and the epicentre $5 \mathrm{~km}$ to NW of the Strug rock fall. Because no large changes were observed in the field, no further measurements were performed.

\section{Results and discussion}

\subsection{Measured datasets}

During 2003 and 2004 seven geodetic campaigns were performed over 5500 points in the Strug rock fall area (Table 3). Figure 4 shows these detailed datasets with the definition of the stations used for the laser measuring system.

\subsection{Analysis of the measured data}

During the measurement set 0 (Table 2), there were no gullies in the area. Because of heavier rainfall (Table 3) a gully started to emerge, and it became visible during the measurement set 1. After that, the gully was changing its form, position and depth. Figure 5 shows the measured changes of the longitudinal profile of this gully between the measurement set 2 , and set 3 . It can be seen that the gully 


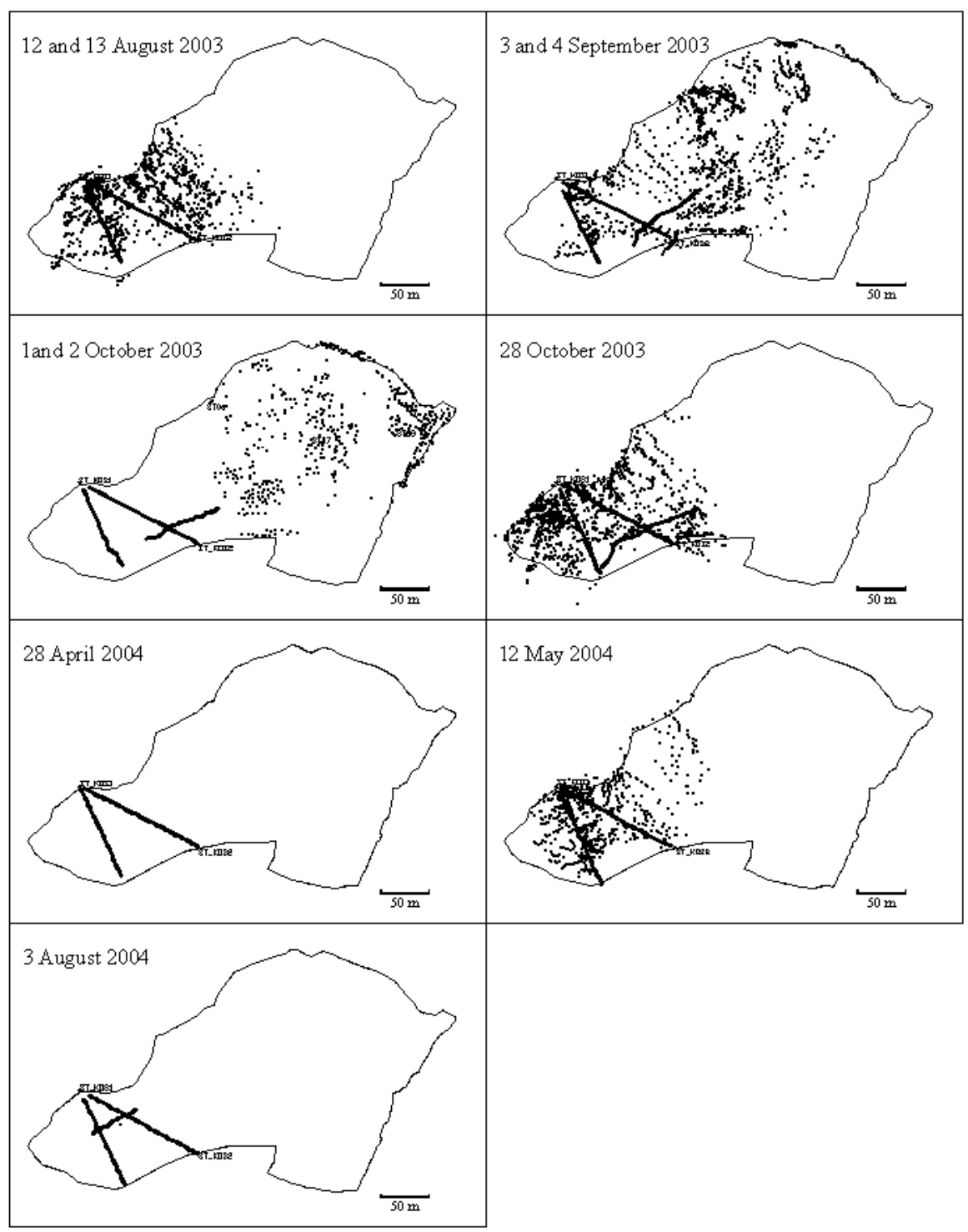

Fig. 4. Measurement sets from 0 to 6 , taken from the station "ST_KOS1".

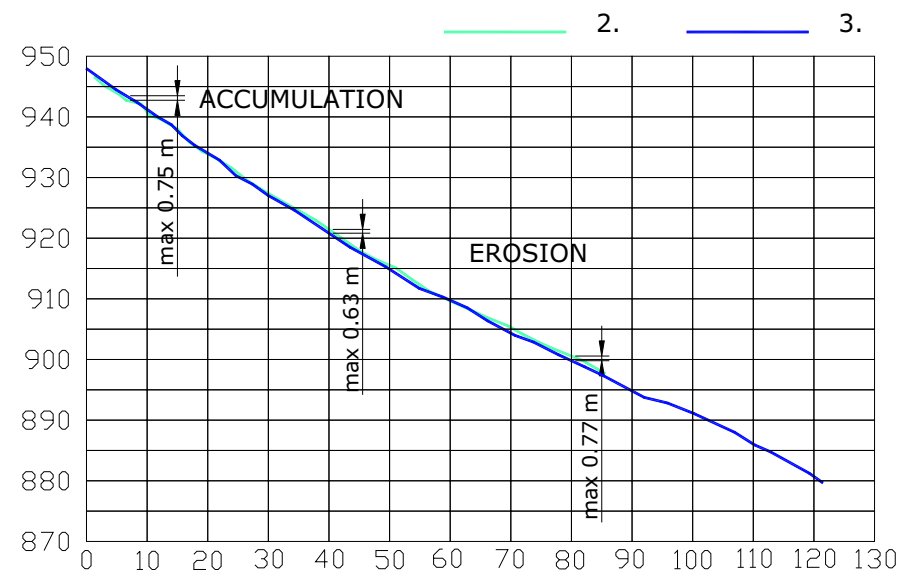

Fig. 5. Comparison of the longitudinal profile of the gully in 2003 for the measurement sets 2 and 3 . 
Table 4. Changes in position of the fixed geodetic points on rocks between selected measurements; rounded values to $1 \mathrm{~cm}$ should be seen within the accuracy of the laser measurement system of $\pm 10 \mathrm{~cm}$ (legend: positive axis $\mathrm{x}$ is oriented towards $\mathrm{E}$, positive axis $\mathrm{y}$ is oriented towards $\mathrm{N}$, and the rock fall steepest gradient is oriented towards SWW, that is to the opposite direction).

\begin{tabular}{|c|c|c|c|c|c|c|c|c|c|c|c|c|c|c|c|c|}
\hline \multirow[b]{2}{*}{ Point ID } & \multicolumn{4}{|c|}{ Measurement set 1 -set 3} & \multicolumn{4}{|c|}{ Measurement set 1 -set 5} & \multicolumn{4}{|c|}{ Measurement set 3 -set 5} & \multicolumn{4}{|c|}{ Measurement set 5 -set 6} \\
\hline & $\Delta \mathrm{x}(\mathrm{cm})$ & $\Delta \mathrm{y}(\mathrm{cm})$ & $\Delta \mathrm{z}(\mathrm{cm})$ & $\Delta \mathrm{l}(\mathrm{cm})$ & $\Delta \mathrm{x}(\mathrm{cm})$ & $\Delta \mathrm{y}(\mathrm{cm})$ & $\Delta \mathrm{z}(\mathrm{cm})$ & $\Delta \mathrm{l}(\mathrm{cm})$ & $\Delta \mathrm{x}(\mathrm{cm})$ & $\Delta \mathrm{y}(\mathrm{cm})$ & $\Delta \mathrm{z}(\mathrm{cm})$ & $\Delta \mathrm{l}(\mathrm{cm})$ & $\Delta \mathrm{x}(\mathrm{cm})$ & $\Delta y(\mathrm{~cm})$ & $\Delta \mathrm{z}(\mathrm{cm})$ & $\Delta \mathrm{l}(\mathrm{cm})$ \\
\hline SK_I & 1 & 2 & -17 & 18 & -6 & -37 & -77 & 86 & -5 & -35 & -95 & 101 & 8 & 17 & -3 & 19 \\
\hline SK_II & 7 & -10 & -25 & 28.7 & -44 & -90 & -111 & 150 & -36 & -100 & -137 & 173 & 4 & -2 & -32 & 32 \\
\hline SK_III & -1 & -4 & -16 & 17 & -5 & -28 & -103 & 107 & -6 & -32 & -119 & 124 & 44 & 80 & -7 & 91 \\
\hline SKIV & -2 & -14 & -27 & 30 & -58 & -57 & -156 & 176 & -60 & -72 & -183 & 206 & 45 & 48 & -38 & 76 \\
\hline SK_V & -2 & -1 & -1 & 3 & & & & & & & & & & & & \\
\hline SK_VII & -3 & -2 & 1 & 4 & & & & & & & & & & & & \\
\hline
\end{tabular}

changed its headcut location and considerably lengthened by approximately $40 \mathrm{~m}$ towards the landslide. In its upper part, at the headcut of the gully, material accumulation of approx. $75 \mathrm{~cm}$ was measured. In its middle and lower parts the gully deepened by $63-77 \mathrm{~cm}$. Later, due to large morphological changes of the rock fall surface, which was between the measurement sets 3 and 5, it disappeared (it was filled up with the falling material). On the western part of the rock fall a new gully was initiated and it was noticed in May 2004 (Fig. 6), but the channel was so deep that it could not be measured using a 2.15-m long pole. In August 2004, this gully was partially filled up and thus shallow enough to be measured.

A comparison for the reference cross section "ST_KOS1ST_KOS2" (Figs. 7 and 8) indicates that the section deepened in 2003 due to erosion of the material from this part of the rock fall. In 2002 numerous debris flows from the area reached the village of Kosec (Mikoš et al., 2005). It can be assumed that the debris material originated from this part of the Strug rock fall source area. In the upper part of the cross section where it cut the gully, up to $1.6 \mathrm{~m}$ of material was eroded, in the middle of the cross section it was less, i.e. only up to $1.0 \mathrm{~m}$. In 2004, the lower part of the cross section remained more or less unchanged. In the upper part of the section, the material from higher parts of the rock fall was firstly accumulating, between the measurement sets 3 and 5 for a maximum of $7.8 \mathrm{~m}$. After that, this part was to a large extent eroded again, between the measurement sets 5 and 6 for a maximum of $7.0 \mathrm{~m}$.

A comparison for the reference cross section "ST_KOS1CD2" for the measurements in 2003 (Fig. 9) and in 2004 (Fig. 10) is shown. It can be seen that the whole cross section deepened (material was eroded) between the measurement sets 0 and 2 . The erosion depth was around $2 \mathrm{~m}$, maximum was $2.6 \mathrm{~m}$. Between the measurement sets 2 and 3, the cross section was partially filled with new falling material, the maximum accumulation depth was $2.0 \mathrm{~m}$. In 2004, the accumulation between the measurement sets 3 and 5 was additional $4.0 \mathrm{~m}$ at its maximum. After that, the cross section was eroded again, between the measurements 5 and 6 for a maximum of $4.0 \mathrm{~m}$.

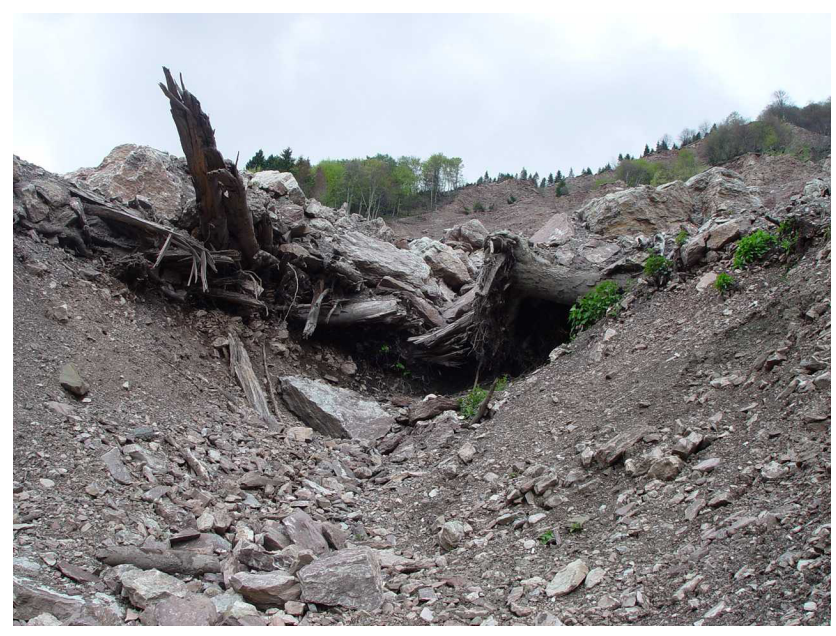

Fig. 6. New gully was part of the measurement set 5 on 12 May 2004.

It should be mentioned that both cross sections were only fixed on both ends and not in-between. Thus smaller errors were associated with the measurements due to the possible shift of points on the rock fall surface when measured the next time. Nevertheless, the interpretation of erosion and accumulation process in this part of the rock fall source area is not misjudged.

During the measurement set 5 two rocks ("SK_V" and "SK_VII") were no more present (they eroded or were covered by falling material). In Table 4, measured displacements of these fixed geodetic points on rocks are given. The largest displacement observed in this period was $206 \mathrm{~cm}$ for the fixed geodetic point on the rock "SK_IV". It can be seen that some measured displacements are close to the laser scanner's accuracy of $\pm 10 \mathrm{~cm}$ and therefore they should be considered within the accuracy limits and thus rather measurement errors. This conclusion is even more stressed by the fact that the vectors of such measured displacements exhibit movements up the slope. Nevertheless, the comparison between measurement sets 1 and 5 , and 3 and 5 shows displacements of the order of $1-2 \mathrm{~m}$. If this value is compared to the average virtual velocity of the rockslide of $1.2 \mathrm{~m}$ a month, measured in 2002 (Mikoš et al., 2005), it becomes clear that the 
Table 5. Estimated changes in $\mathrm{m}^{3}$ per $1 \mathrm{~m}$ along the cross sections "ST_KOS1-ST_KOS2" and "ST_KOS1-CD2" for selected periods (estimated volumes are rounded to $1 \mathrm{~m}^{3}$ ).

\begin{tabular}{|c|c|c|c|c|c|}
\hline Period & 12 August-28 October 2003 & 12 August 2003-12 May 2004 & 12 August 2003-3 August 2004 & 28 October 2003-12 May 2004 & 12 May-3 August 2004 \\
\hline Measurement sets & $0-3$ & $0-5$ & $0-6$ & $3-5$ & $5-6$ \\
\hline \multicolumn{6}{|c|}{ Reference cross section "ST_KOS1-ST_KOS2" } \\
\hline Accumulated material & +2 & +347 & +13 & +400 & +5 \\
\hline Total change & -52 & +339 & -19 & +395 & -359 \\
\hline \multicolumn{6}{|c|}{ Reference cross section "ST_KOS1-CD2" } \\
\hline Accumulated material & +4 & +105 & +35 & +156 & +5 \\
\hline
\end{tabular}

0.

1.

2.

3.

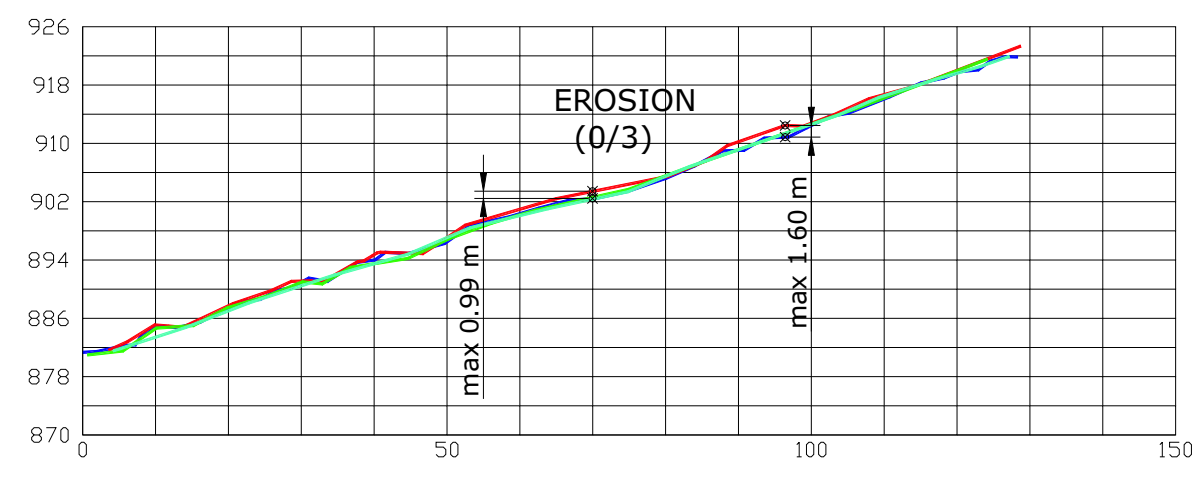

Fig. 7. A comparison of the reference cross section "ST_KOS1-ST_KOS2" for the measurement sets in 2003.

rockslide and the rock fall activity slowed down in 2003 and 2004 when compared to their initial activity in 2002 after the initiation in December 2001.

5.3 Analysis of volumetric changes in the reference cross sections

An analysis of volumetric changes on the rock fall area was performed using the measured changes in the reference cross sections "ST_KOS1-ST_KOS2" and "ST_KOS1-CD2". Due to the size of the Strug rock fall area, its hard accessibility and steep terrain, only these two cross sections were selected to perform measurements in them in order to estimate terrain changes. In Table 5 estimated changes in $\mathrm{m}^{3}$ per $1 \mathrm{~m}$ along the cross sections are given for the before mentioned measurements The analysis shows that:

- in 2003 the cross section "ST_KOS1-ST_KOS2" exhibited only minor changes. In some parts nearly $2 \mathrm{~m}^{3} / \mathrm{m}$ ' of material was accumulated, and in other parts more or less uniformly about $54 \mathrm{~m}^{3} / \mathrm{m}^{3}$ of material was eroded. The mass balance was $52 \mathrm{~m}^{3} / \mathrm{m}$ ' of eroded material for this period. During winter 2003/2004 a large accumulation of $400 \mathrm{~m}^{3} / \mathrm{m}$ ' was measured with only minor erosion of $5 \mathrm{~m}^{3} / \mathrm{m}$ '. Next large change in the section was measured in August 2004 when altogether $359 \mathrm{~m}^{3} / \mathrm{m}^{\prime}$ of material was eroded from the section.
- the cross section "ST_KOS1-CD2" also exhibited low activity in 2003. In some parts of this section, $4 \mathrm{~m}^{3} / \mathrm{m}$ ' of material accumulated whereas elsewhere $75 \mathrm{~m}^{3} / \mathrm{m}$ ' of material was eroded. The mass balance was $71 \mathrm{~m}^{3} / \mathrm{m}^{\prime}$ of eroded material for this period. During winter $2003 / 2004$ a large accumulation of $156 \mathrm{~m}^{3} / \mathrm{m}$, was measured with only minor erosion of $1 \mathrm{~m}^{3} / \mathrm{m}$ '. The next large change in the section was measured in $\mathrm{Au}$ gust 2004 when altogether $139 \mathrm{~m}^{3} / \mathrm{m}$ ' of material was eroded from the section.

The material eroded from the rock fall surface by overland flow and from both observed gullies by channel flow was transported in the form of sediment laden flows and not as debris flows. The eroded material was rather fine and the coarser fractions accumulated in the channel in the landslide area and did not reach the village of Kosec as debris flows observed in 2002.

5.4 Comparison between topography from aerial photographs and measured by the laser measurement system

A new set of aerial photographs was taken on 28 December 2001, just a few days after the Strug rock fall was triggered. A 3-D model of the terrain after the event was prepared using TIN and computer software QuickSurf (Fig. 11a). The same approach was used with field 2003 Laser data system. 
3.

4.

5.

6.

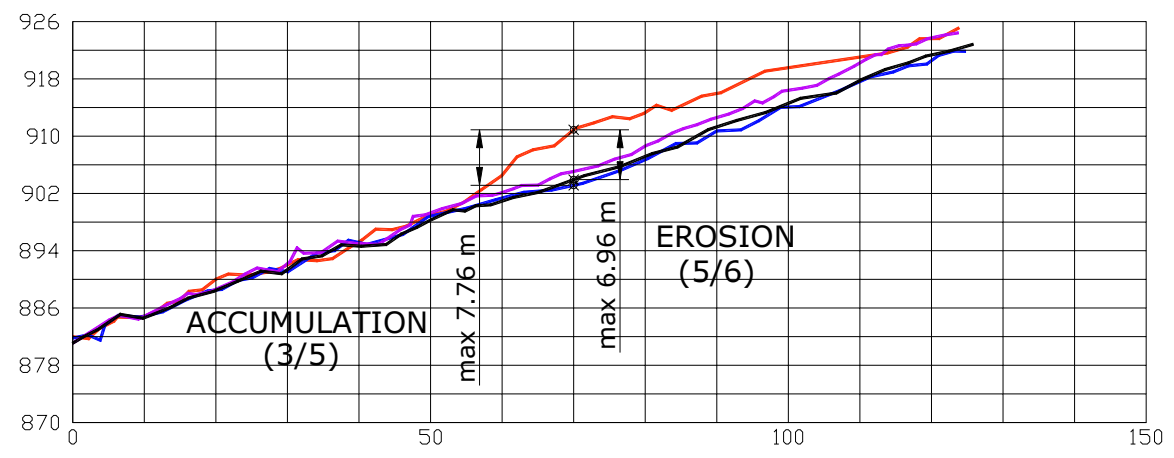

Fig. 8. A comparison of the reference cross section "ST_KOS1-ST_KOS2" for the measurement sets in 2004.

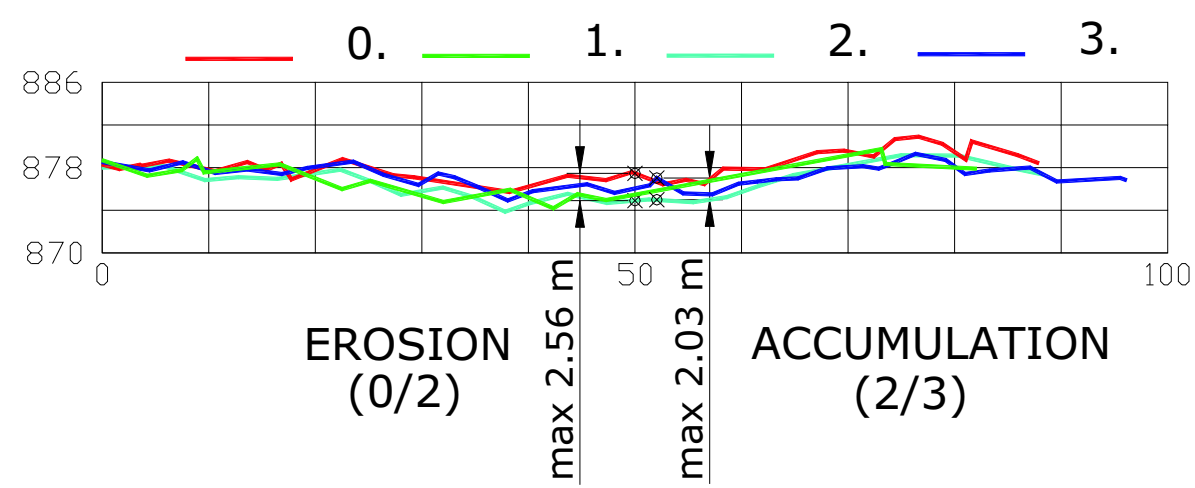

Fig. 9. A comparison for the reference cross section "ST_KOS1-CD2" for the measurement sets in 2003.

The TIN (Fig. 11b) is less dense as when using data from the interpretation of aerial photographs (Fig. 11a). The main cause is on one hand that this part of the source area is hard to access on foot for active measurements using the laser and reflectors, and on the other hand its surface does not reflect laser beam very well with passive measurements.

On Fig. 11 also the locations of the three selected longitudinal profiles in the Strug rock fall area are given, used for a comparison of the Strug rock fall area changes between August 2000 and September 2003 (Fig. 12). The diagram shows well that the material was eroded in the upper part of the rock fall by up to $20 \mathrm{~m}$, and accumulated in its lower part by up to $10 \mathrm{~m}$.

\section{Conclusions}

The described approach using a reflectorless laser measurement system proved a cost-effective way of monitoring the Strug rock fall area in order to detect significant morphological changes. The following general conclusions can be drawn from this case study:

1. The LaserAce ${ }^{\circledR} 300$ measuring system provided a useful, handy and highly adequate solution for remote measurements in rock fall source areas, even though it has been tested only in a rock fall area during a period of low activity. Good weather conditions are needed to deploy this type of equipment.

2. Relatively small changes of the rock fall surface relevant for understanding the rock fall activity and development were successfully measured. The equipment made it possible to manually digitise the specific features on the terrain to focus on significant processes during data gathering rather than during data handling and their interpretation.

3. Choosing a point cloud with a density of less than 1 point per $10 \mathrm{~m}^{2}$ on a very rough rock fall surface failed to be a good solution. The changes on larger areas were shown by displacements of selected significantly largesized rock blocks with a volume of several $\mathrm{m}^{3}$.

4. Local surface changes of the order of $1 \mathrm{~m}$ or more, were clearly shown by measurements in the selected referenced cross sections. The usage of these cross sections gave a possibility to evaluate volumetric changes on the rough rock fall surface.

The following conclusions regarding the better understanding of the Strug rock fall evolution can be drawn from this case study: 


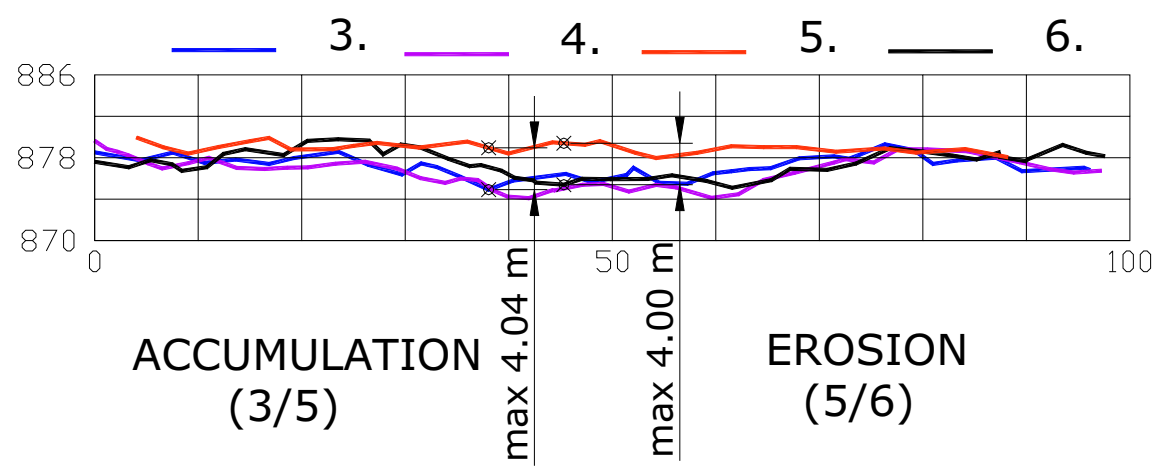

Fig. 10. A comparison for the reference cross section "ST_KOS1 - CD2" for the measurement sets in 2004.

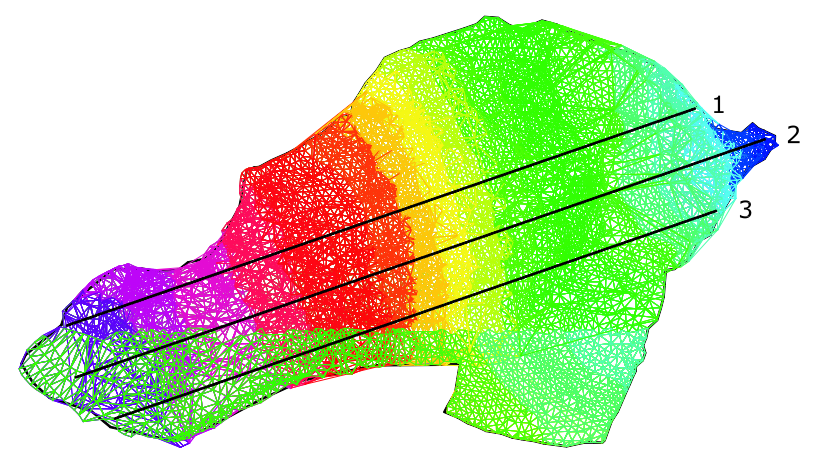

Fig. 11a. 3-D TIN model of the Strug rock fall area derived from the aerial photographs taken on 28 December 2001, just after the initiation of the rock fall. Position of the three selected longitudinal profiles for their time evolution comparison are also given.

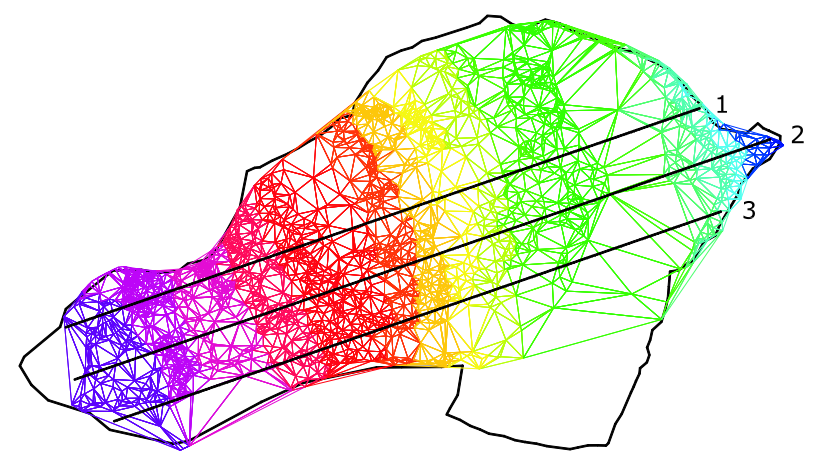

Fig. 11b. 3-D TIN model of the Strug rock fall source area derived from geodetic measurements in September 2003 using laser scanner measurement system. Position of the three selected longitudinal profiles for their time evolution comparison are also given.

1. In 2003 and 2004, in the Strug rock fall area rainfall and overland flow were the major erosive forces combined with channel flow in gullies and gravity. Precipitation on bare rock fall surface caused fast surface runoff and therefore some surficial soil detachment, mainly wash- ing away of finer fractions from the rather coarse rock fall debris. Significant morphological changes on the rock fall surface were of local character only. They developed mainly in the middle southern part of the rock fall source, where each year developed one gully.

2. Lower rock fall activity in 2003 and 2004 and reduced supply of coarse debris material together with the enlarged accumulation capacity of the landslide area after frequent debris flows in 2002, seems to be the major cause why no debris flows were observed in 2003 and 2004. Even though the anticipated rainfall triggering limit of $30 \mathrm{~mm}$ a day was reached several times. The material eroded from the rock fall area was finer than in 2002 and transported in the form of sediment laden flows and not as debris flows.

3. As proposed by Mikoš et al. (2005), the process of debris flow generation in the Strug rock fall source area is a material-governed process. The numerous debris flows observed in 2002 have emptied the rock fall debris in the lower accumulation part of Strug rock fall as well as their temporary deposits on the landslide surface below the rock fall. For initiation of new debris flows, reintensification of the rock fall is needed.

Acknowledgements. B. Stopar and T. Ambrožic assisted by GPS-related field measurements. M. Padežnik, L. Smrkolj, U. Stibilj and A. Bilc performed field scanner measurements. Their contribution is greatly acknowledged. L. Smrkolj helped with data analysis and preparation of graphic files. The indepth reviews of M. Jaboyedoff and A. Tamburini greatly improved the first version of the paper.

Edited by: M. Jaboyedoff

Reviewed by: R. Caloz and A. Tamburini 

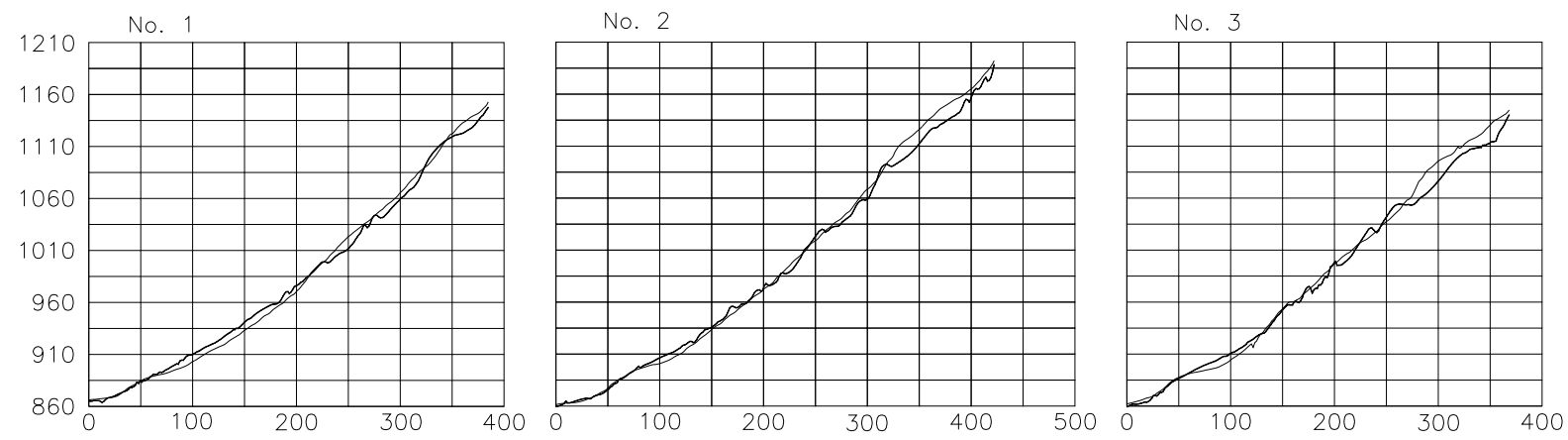

Fig. 12. Three longitudinal profiles of the Strug rock fall - comparison between 3-D TIN models of December 2001 (thin lines) and September 2003 (thick lines).

\section{References}

Angeli, M-G., Pasuto, A., and Silvano, S.: A critical review of landslide monitoring experiences, Eng. Geol., 55, 133-147, 2000.

Autodesk: http://www.autodesk.com/, 2004.

Bitelli, G., Dubbini, M., and Zanutta, A.: Terrestrial laser scanning and digital photogrammetry techniques to monitor landslide bodies, in: Proceedings of the XXth ISPRS Congress, Istanbul, Vol.XXXV, part B5, 246-251, 2004.

D'Agostino, V. and Marchi, L.: Debris flow magnitude in the Eastern Italian Alps: data collection and analysis, Physics and Chemistry of the Earth, Part C, 26, 657-663, 2001.

Gili, J. A., Corominas, J., and Rius, J.: Using Global Positioning System techniques in landslide monitoring, Eng. Geol., 55, 167192, 2000.

Hunter, G., Pinkerton, H., Airey, R., and Calvari, S.: The application of a long-range laser scanner for monitoring volcanic activity on Mount Etna, J. Volc. Geoth. Res., 123, 203-210, 2003.

Jaboyedoff, M., Ornstein, P., and Rouiller, J.-D.: Design of a geodetic database and associated tools for monitoring rock-slope movements: the example of the top of Randa rockfall scar, Nat. Haz. Earth Sys. Sci., 4, 187-196, 2004,

SRef-ID: 1684-9981/nhess/2004-4-187.

Leica: http://www.leica.com/, 2004.

Listech: http://www.liscad.com/liscad/, 2004.
Marchi, L. and D'Agostino, V.: Estimation of debris-flow magnitude in the Eastern Italian Alps, Earth Surface Processes and Landforms, 29, 207-220, 2004.

MDL: http://www.mdl.co.uk/, 2004.

Microsoft: http://www.microsoft.com/, 2004.

Mikoš, M., Brilly, M., Fazarinc, R., and Ribicic, M.: Strug landslide in W Slovenia: a complex multi-process phenomenon, Eng. Geol., in print, 2005.

Mora, P., Baldi, P., Casula, G., Fabris, M., Ghirotti, M., Mazzini, E., and Pesci, A.: Global Positioning Systems and digital photogrammetry for the monitoring of mass movements: application to the $\mathrm{Ca}$ ' di Malta landlside (northern Appenines, Italy), Eng. Geol., 68, 103-121, 2003.

Scheikl, M., Grafinger, H., and Poscher, G.: Entwicklung und Einsatz eines automatischen Fernüberwachungssystems basierend auf einem Laserscanner (ALARM), in: Proceedings of the 11. Internationale Geodätische Woche, Obergurgl, Austria, 18.24.2.2001, 205-213, 2001.

Schreiber: http://www.schreiber.com/, 2004.

Tarchi, D., Casagi, N., Fanti, R., Leva, D.D., Luzi, G., Pasuto, A., Pieraccini, M., and Silvano, S.: Landslide monitoring by using ground-based SAR interferometry: an example of application to the Tessina landslide in Italy, Eng. Geol., 68, 15-30, 2003.

Trimble: http://www.trimble.com/, 2004. 